\title{
The Introduction and Breeding of Vaccinioideae in Russia
}

\author{
Aleksey Gorbunov ${ }^{1 *}$, Galina Tyak ${ }^{2}$, and Valeriy Makeev ${ }^{2}$, and Tatyana Kurlovich ${ }^{3}$ \\ ${ }^{1}$ Central Siberian Botanical Garden SB RAS, 630090, Novosibirsk, Russian Federation \\ ${ }^{2}$ Central European Forest Experimental Station ARRISMF, Kostroma, Russian Federation \\ ${ }^{3}$ SSI «Central Botanical Garden of NAS of Belarus», 220012, Minsk, Surganova st. 2v, Belarus
}

\begin{abstract}
This article briefly reviews the history of researching the introduction and breeding of cranberry, blueberry and cowberry in the world. The results and prospects of research in these areas in the CSBS SB RAS and the CEFES ARRISMF are presented. The article shows the effectiveness of selecting from natural populations promising material for introduction and breeding, and also the usage of intraspecific and interspecific hybridization for Vaccinioidaea breeding. As a result of longterm studies, the collections of Vaccinioidae were made in Russia. In CSBG SB RAS it totals 7 species, 1 subspecies, 54 varieties, 8 hybrids, 101 forms, including 64 selections and world's first 8 varieties of Vaccinium uliginosum. In CE FES ARRISMF it totals 7 species, 1 subspecies, 82 varieties, 40 hybrids, 58 forms including 40 selections and the first Russian 7 varieties of Oxycoccus palustris and 3 varieties of Vaccinium vitis-idaea.
\end{abstract}

The following Vaccinioideae Arn. are introduced into industrial culture: Oxycoccus macrocarpus (Aiton) Pers., Oxycoccus palustris Pers. (mostly the hexaploid race, 2n=72), Vaccinium corymbosum L., or highbush blueberry and its interspecific hybrids, Vaccinium angustifolium Aiton, or lowbush blueberry, Vaccinium virgatum Aiton, or rabbiteye blueberry, artificial interspecies hybrids $V$. corymbosum $\times V$. angustifolium, or half-high blueberry and Vaccinium vitis-idaea L., or cowberry. Russia, Belarus and China are working at introducing Vaccinium uliginosum L. [1-4]. In order to undertake the study, collections were made. These collections includes 7 species, 1 subspecies, 54 varieties, 8 hybrids, 101 forms including 46 selections (164 specimens total) and the world's first 8 varieties of Vaccinium uliginosum in CSBG SB RAS, and 7 species, 1 subspecies, 82 varieties, 40 hybrids, 58 forms including 40 selections (141 specimens in total), and the first Russian 7 varieties of Oxycoccus palustris and 3 varieties of Vaccinium vitis-idaea in CE FES ARRISMF.

The main producers of fresh and processed cranberry are USA and Canada; blueberry USA, Canada, and Chili; cowberry - Germany and Scandinavian countries.

In Russia Oxycoccus macrocarpus was first introduced in Saint Petersburg Botanical Garden at the end of XIX century [5]. Intensive introduction research was started in 1968 in the Main Botanical Garden AS USSR (MBG, Moscow) and in the Central Siberian

\footnotetext{
* Corresponding author: gab_2002ru@ngs.ru
} 
Botanical Garden SB AS USSR (CSBG, Novosibirsk). In 1976, CE FES (former Kostroma Forest Experimental Station, Kostroma) joined the research. Russia's only large industrial plantation where Oxycoccus macrocarpus occupies about 140 hectares is located in Kostroma Oblast.

During the 200-year period of Oxycoccus macrocarpus cultivation based on selection in nature and cross-variety hybridization, over 100 varieties were developed in USA. The most popular of these varieties are 'Ben Lear', 'Bergman', 'Pilgrim', 'Stevens', 'Franklin', 'Howes', 'McFarlin', 'Wilcox', 'Crowley' and 'Early Black'. The experience of studying 42 North American varieties in the CSBG over 52 years and experience of studying 26 varieties in CE FES ARRISMF over 20 years showed that only the most early-maturing varieties, such as 'Ben Lear', 'Black Veil' and 'Early Black', can fully ripen in these regions. It is interesting to note that in Siberia, the middle-maturing variety 'Bergman' behaves like an early-maturing variety, the early-maturing variety' Ben Lear 'and the latematuring variety' Pilgrim' - like a medium-maturing variety. Berries of varieties 'Ben Lear' and 'Pilgrim' can ripen at the ambient temperature $+5{ }^{\circ} \mathrm{C}$ during storage [6]. 3 forms of large-fruited cranberry obtained by intraspecific hybridization, which surpass a number of tested varieties in early maturation and some economically valuable characteristics, were selected in the CE FES.

Oxycoccus palustris was first introduced in Royal Botanic Gardens, Kew in Great Britain in 1789. In Russia it was introduced at the end of XIX century [5]. In Russia, the intensive introduction research of Oxycoccus palustris was started in 1965 in the CSBG, in 1974 in the Institute of Biology of the Karelian Branch of the AS USSR, in 1976 in Kostroma FES. In 2003, for the first time in Russia the work on establishment of an industrial plantation of cranberry began in Kostroma Oblast under scientific supervision and with direct participation of CE FES. The varieties and commercially valuable forms of Oxycoccus palustris occupied about 6 hectares. With scientific and methodological assistance of CE FESs researchers, a large industrial plantation was initiated in Arkhangelsk Oblast in 2016. Mother-plantations of varieties and commercially valuable forms of Oxycoccus palustris were laid. Similar mother-plantations were laid in KhantyMansiysk Autonomous Region (Yugra).

The world's first 6 varieties of Oxycoccus palustris were developed in Estonia by selecting from wild populations ('Virussaare', 'Soontagana', 'Maima', 'Nigula', 'Kuressoo', 'Tartu'). From these varieties, 'Virussaare' is the one that is most interesting for introduction and breeding under conditions of Kostroma Oblast and the south of Western Siberia. Using the same method in CE FES, Russia's first 6 varieties of Oxycoccus palustris were developed ('Alaya zapovednaya', 'Krasa Severa', 'Sazonovskaya', 'Severyanka', 'Sominskaya', 'Hotavetskaya'). The variety 'Dar Kostromy' was developed by selection from massive crops. In addition, based on an integrated set of features, CE FES distinguished 8 selective forms of Oxycoccus palustris developed as a result of intraspecific hybridization. These forms surpass the existing varieties in some commercially valuable features.

The first attempts to introduce blueberry into the industrial culture were made in the late XIX - early XX centuries in USA. Since 1923 and especially 1980s until present days, blueberry has widely spread across the continents. The largest areas and quantities of production were recorded in USA, Canada, and Chili. 16 countries take part in commercial production of blueberry.

In Russia, the work on introducing Vaccinium corymbosum L. [1-4] into industrial culture began in 1964 in MBG, in 1983 in CSBG and in CE FES, and in 1990 in AllRussian Research Institute of Horticulture (Michurinsk). The work on introducing Vaccinium angustifolium began in 1970 in MBG, in 1981 in CSBG and in 1999 in CE FES. The work on introducing half-high blueberry began in 1990 in CSBG and in 2003 in CE 
FES. The work on introducing Vaccinium virgatum began in 1990 in CSBG. The work on introducing Vaccinium uliginosum began in 1966 in MBG, in 1969 in CSBG, in 1975 in the Institute of Biology KRC RAS and in 1986 in CE FES [2].

Since 2004, blueberry has been grown on 6 hectares of an industrial plantation. This planting was carried out from seed progenies of half-high blueberry and Vaccinium angustifolium with scientific and methodological assistance of CE FES researchers.

Over 360 varieties of Vaccinium corymbosum, half-high blueberry, Vaccinium angustifolium and Vaccinium virgatum are presently known. These varieties were developed by horticulturists from the USA [8].

32 forms prospective for introduction into industrial culture have been developed from seed progenies of 'Northblue' and 'Putte' varieties in CE FES. The world's first 8 varieties of Vaccinium uliginosum ('Tayozhnaya krasavitsa', 'Golubaya rossyp', 'Shegarskaya', 'Yurkovskaya', 'Divo', 'Nektarnaya', 'Izyashchnaya', 'Iksinskaya') were developed in CSBG. 3 varieties of this species were developed in China ('Ametist', 'Hingan-1', 'Czyshujczin'), and 1 variety was developed in Belarus ('Pamyati Volchkova'). In addition, CSBG distinguished 11 selections and CE FES distinguished 5 selections by a complex of features.

Vaccinium virgatum is more a warm-season plant. However, its varieties 'Salaspils Izturīgā' and 'Lielogu' by Lettish breeding are promising for Russia by a complex of features [9]. The first variety is a result of open pollination of 'Tifblue' variety. The other one is a cross-variety hybridization of 'Delite' $\times$ 'Woodard'.

Information about the first attempts of cowberry cultivation for decorating parterres in Tsarskoe Selo Garden (Saint-Petersburg) dates back to 1745. [10].

Since 1966, Sweden, Finland, Norway, Ukraine, Holland, Lithuania, Poland, USA. Russia and China have intensively started the research on cowberry introduction [11].

Most progress in cowberry cultivation was made by Germany, where the area under crops amounted to 35 hectares in the 1990s. In Russia, the best results in introduction and breeding of cowberry were made by CE FES (Kostroma).

23 varieties of cowberry are presently known. The Dutch variety 'Koralle' is regarded as the best. 3 varieties were developed by selection from wild populations in CE FES ('Kostromskaya rozovaya', 'Kostromichka' and 'Rubin'). Also, 8 forms of cowberry prospective for introduction and breeding were developed by intraspecific hybridization.

Intraspecific hybridization is an effective method of Vaccinioideae breeding. Regarding the fact that the most part of Russia's territory appropriate for Vaccinioidaea cultivation is an area with insufficient heat supply, the early-season and mid-season varieties play the key role in the breeding programs. 'Ben Lear', 'Pilgrim', 'Bergman', 'Franklin' and 'Stevens' are of interest in intraspecific (cross-variety) crossings of Oxycoccus macrocarpus varieties. 'Virussaare', 'Dar Kostromy', 'Krasa Severa', 'Sazonovskaya' and selected by researchers of the Institute of Biology KRC RAS form $15 \mathrm{~V}$ with large berries are of interest in crossings of Oxycoccus palustris varieties. 'Bluetta', 'Weymouth', 'Duke', 'Hardyblue', 'Coville', 'Patriot' are of interest in crossings of Vaccinium corymbosum. 'Northblue', 'Northcountry' and 'Northland', one form selected by CSBG researchers, and 12 forms selected by CE FES researchers are of interest in crossings of half-high blueberry. 'Blomidon', 'Arne', 'Motego', 'Polovchanka', 'Yanka' are of interest in crossings of Vaccinium angustifolium. 'Tayozhnaya krasavitsa', 'Golubaya rossyp' researchers are of interest in crossings of Vaccinium uliginosum. 'Koralle', Erntesegen, 'Erntekrone', 'Kostromskaya rozovaya', 'Kostromichka', 'Rubin' and selections of the CE FES are of interest in crossings of Vaccinium vitis-idaea. Among the intraspecific hybrids of Oxycoccus palustris selected by CE FES researchers, the form 1-15-635 is prospective for introduction and breeding. It is characterized by high productivity and large berries of good quality [12]. The yield of this form is $1231 \mathrm{~g} / \mathrm{m}^{2}$ by the third year and $2650 \mathrm{~g} / \mathrm{m}^{2}$ by the fifth 
year, with an average mass of 100 berries, respectively, being 223 and $176 \mathrm{~g}$ and the maximum mass of one berry $-4.47 \mathrm{~g}$.

Interspecific hybridization is the most effective method of Vaccinioidaea breeding. Almost the whole industrial range of the varieties of Vaccinium corymbosum has been developed by this method [13]. 'Aron' and 'Arne' varieties were developed in Finland by crossing Vaccinium uliginosum and Vaccinium corymbosum $[14,15]$. Similar hybrids were developed in Russia, Lithuania, Poland, and Belarus.

Hybrids of artificial tetraploid (colchiploid) of Oxycoccus macrocarpus and Oxycoccus palustris were developed in USA [16].

In developing the varieties for Russia, the hybrids of Oxycoccus macrocarpus and Oxycoccus palustris are of considerable interest. However, by reason that the second species is represented in nature mostly by hexa- $(2 n-72)$ and tetraploids $(2 n=48)$, and the first one by a diploid $(2 n=24)$, the interspecific hybrids are only developed at the tetraploid level [17]. Meanwhile, Oxycoccus macrocarpus was transferred to the tetraploid level by using colchicine.

In order to create the technological varieties of cowberry, interspecific hybrids of Vaccinium reticulatum and Vaccinium vitis-idaea were created in the USA [18]. Vaccinium reticulatum is an evergreen tall-growing (to 1,3, less often 2,0 m) shrub with red or purple berries reaching $14 \mathrm{~mm}$ size, diploid $(2 \mathrm{n}=24)$.

The most prospective combinations of interspecific crossings in Russia are: for cranberry - Oxycoccus macrocarpus (artificial polyploid $2 \mathrm{n}=48,72) \times$ O. palustris; for blueberry - Vaccinium corymbosum $\times V$. angustifolium, $V$. uliginosum $\times V$. corymbosum, $V$. uliginosum $\times($ V.corymbosum $\times V$. angustifolium $)$ and $V$. uliginosum $\times V$. angustifolium; for lingonberry $-V$. reticulatum $\times V$. vitis-idaea. The hybrids $V$. uliginosum $\times($ V.corymbosum $\times V$. angustifolium) were developed in CSBG by using the in vitro embryo culture. Crossing interspecific hybrids among themselves and obtaining seedlings from seeds from their free pollination is another promising direction of research.

Studies to determine the possibilities of creating intergeneric hybrids of Vaccinioideae have been carried out in the USA, Germany, Russia, Lithuania, and Belarus since 1940s. The hybrids of Vaccinium ovatum and Oxycoccus macrocarpus, Oxycoccus macrocarpus and Vaccinium vitis-idaea, Vaccinium corymbosum and Oxycoccus palustris have been obtained in USA [16]. Since 1969, similar research has been conducted in Finland. During reciprocal crossings, the hybrids of Vaccinium microcarpum (= Oxycoccus microcarpus Turch. Ex Rupr.) and Vaccinium vitis-idaea [19], as well as the hybrids of Vaccinium vitis-idaea and Oxycoccus macrocarpus, have been obtained [20]. The berries set only in such combinations where Vaccinium macrocarpon was a male plant. All the hybrids obtained in Finland proved to be sterile. Intergeneric hybrids that were obtained in Germany also turned out to be sterile [21].

The research into intergeneric hybridization of Vaccinioideae in Russia was held in 1984-2006. 18 combinations of crossings were made. 13 of these crossings proved to be resultative [22]. The highest chance of the berries set was noted in the crossing of Oxycoccus palustris and Vaccinium angustifolium (100\%) and Vaccinium corymbosum $(83 \%)$. The least chance (12\%) was noticed in the crossing of Oxycoccus palustris and Vaccinium virgatum. The berries lacked seeds, the seeds had a low chance to set, and the seedlings gradually died.

On the basis of intergeneric crossings of Oxycoccus macrocarpus and Vaccinium vitisidaea that were made in Latvia in 1987-1990, the first fertile, high-yielding, high-quality and stable cowberry-cranberry hybrids 'Salaspils Agrās', 'Dižbrūcklene', and 'Tina' were developed by processing the hybrid seeds with $0.5 \%$ colchicine for $24 \mathrm{~h}$.

The studies that were carried out in 1985-2004 in Belarus [23] showed the possibility of obtaining hybrids from crossing diploid Vaccinium vitis-idaea with tetraploid Oxycoccus 
palustris and diploid Oxycoccus macrocarpus. The $\mathrm{F}_{1}$ hybrids turned out to be sterile. The attempts to overcome their sterility by forced self-pollination, backcrossing and colchicination of apical meristems of actively growing shoots failed, suggesting the necessity to create initially tetraploid components of crossing.

The intergeneric hybrids of Vaccinium reticulatum and Vaccinium macrocarpon were developed in 1994 at the University of Wisconsin [17]. However, they turned out to be sterile.

The most promising course for Russia consists in creating intergeneric hybrids of Vaccinium macrocarpon and Vaccinium vitis-idaea using the method of the Latvian scientists [9].

Inbreeding, apomixis, physical and chemical mutagenesis were not used in breeding of the Vaccinioideae. However, according to Galleta G.J. [24], many hybrid varieties of Vaccinium corymbosum and Vaccinium virgatum can be considered as partially inbreeding, since their ancestors such as the varieties 'Rubel', 'Russell', 'Brooks' and 'Ethel' are found in the genealogy of one of the parental plants.

Polyploidy was used not only for obtaining remote hybrids of the Vaccinioideae, but also for developing promising polyploid varieties and hybrids of Vaccinium macrocarpon, characterized by high fertility, high-yielding, large berries and formation of numerous flower buds on the shoots [25]. The use of the natural tetraploid of the cowberry $(2 n=48)$ found in the natural environment of Kolyma [26] for the Vaccinioideae breeding is also of considerable interest.

\section{References}

1. G. V. Tyak, S. A. Altuhova, Introduction of Vaccinium uliginosum, Contemporary challenges of nature management, hunting and animal breeding (Kirov, 2002)

2. A. B. Gorbunov, T. I. Snakina, Blueberry, introduction of non-traditional fruit, berry, and vegetable plants in Western Siberia (Novosibirsk, Geo, 2013)

3. L. A. Evtukhova, Plantation cultivation of blueberries (Vaccinium uliginosum L.) in the south-east of Belarus) (Gomel, 1990)

4. Ven Hajlun, Van Fude, Van Sin, Tyan Sinhua, Van Fen, Shi Deshan. Selection of the best blueberry variety Amethyst, Protection and rational use of forest resources (Blagoveshchensk, 2015)

5. E. Regel The large-fruited American cranberry, Bulletin of the Imperial Russian Society of Gardeners (Saint Petersburg., 1871)

6. A. B. Gorbunov, T. A. Kukushkina, Chemistry of plant raw materials, 2 (2019)

7. N. B. Pavlovskij, The taxonomy of blueberries of the Cyanococcus section, Experience and prospects of cultivation of berry plants of the Vacciniaceae family on the territory of Belarus and neighboring countries (Minsk, 2017)

8. A. B. Gorbunov, T. I. Snakina, Blueberry, Introduction of non-traditional fruit, berry, and vegetable plants in Western Siberia (Novosibirsk, Geo, 2013)

9. A. Ripa, B. Audrina, Rabbiteye blueberry, American cranberry and lingonberry breeding in Latvia, Latv. J. Agr., 12 (2009)

10. M. E. Ignatieva, The experience in the cultivation of cowberry as an ornamental plant, Silviculture, forestry and soil science (Leningrad, 1983)

11. N. B. Pavlovskij, N. N. Ruban, Varietal cowberry in the Belarusian Polesie (Minsk, Technology, 2000) 
12. V. A. Makeev, G. Yu. Makeeva, The promising intraspecific hybrid of Oxicoccus palustris, Vaccinioideae culture. (Minsk, 2005)

13. P. Eck, N. F. Childers, Blueberry culture (New Brunswick, Rutgers University Press, 1966)

14. H. Hiirsalmi, A. Lehmushovi, A Finnish highbush blueberry variety. Aron, Ann. Agric. Fenn., 21 (1982)

15. A. Lehmushovi, New blueberry varieties, Annual reports, 1995-1996 (Piikkiö. 1998)

16. G. M. Darrow, Blueberry and cranberry breeding, In: T. Roemer, W. Rudorf: Handbuch der Pflanzenzüchtung, $2^{\text {nd }}$ ed. (Parey, 1960)

17. R. Hagan, J. Polashock, N. Vorsa, P.E Marucci, Vaccinium macrocarpon $\times V$. oxycoccus $(2 n=2 x=24)$ hybrids, Their potential for breeding and genetic mapping in cranberry, $7^{\text {th }}$ International Symposium on Vaccinium Culture, Termas de Chillán, (2000).

18. E. L Zeldin., B.H. McCown, Intersectional hybrids of lingonberry (Vacciniun vitisidaea, section vitis-idaea) and cranberry (V. macrocarpon, section oxycoccus) to Vaccinium reticulatum (section macropelma), Acta Hort. (1997)

19. H. Ahokas, Artificial, reciprocal hybrids between Vaccinium microcarpum and V. vitis-idaea, Ann. Bot. Fennici, 16 (1979)

20. A. Lehmushovi, H. Hokkanen, and H. Hiirsalmi, Cranberry breeding in Finland, Acta Hort. (1993)

21. E. Christ, Crossbreedings between cranberries (Vaccinium macrocarpon Ait.) and cowberries (Vaccinium vitis-idaea L.), Acta Hort. (1977)

22. A. B. Gorbunov, The cranberry. Introduction of non-traditional fruit, berry, and vegetable plants in Western Siberia (Novosibirsk, Geo, 2013)

23. O. V. Morozov, Scientific bases of culture and breeding of cowberry (Vaccinium vitisidaea L.) (Minsk, 2005)

24. G. J. Galleta, Blueberries and cranberries, Fruit plant breeding (Moscow, 1981)

25. E. L. Zeldin, B. H. McCown. Towards the development of a highly fertile polyploid cranberry, $7^{\text {th }}$ International Symposium on Vaccinium Culture (Termas de Chillán, 2000)

26. A. U. Marozay̆, Autotetraploids of Vaccinium vitis-idaea L. under natural conditions, News of the AS of Belarus, Biology, 2 (1995) 